\title{
Changing paradigms: towards competency-assessment in admission to master's programmes in Europe: a review
}

\author{
Kees Kouwenaar*
}

doi: 10.18543/tjhe-3(1)-2015pp99-135

\begin{abstract}
The majority of efforts to improve admission to master's programmes in Europe for students with a bachelor's from outside the providing university have been focused on standardization of defined outcomes of bachelor's degrees and improvement in mechanisms for recognition of diplomas and degree. With growing diversity within and around these master's programmes, an alternative approach to master's admission is needed. This article analyses the nature and shortcomings of the standardisation and the recognition approach and reports on the creation of a competency-assessment based approach in the Mastermind Europe project. In that project - part of the EU's ERASMUS+ programme - Guiding Tools are produced for academic directors of master's programmes (or 'academic masters directors') who want to base their admission decisions less on recognition of a diploma and more on assessment of the applicants' competency. The Guiding Tools focus on specific categories of admission criteria, on how they can be brought together in a coherent framework and on IT tools to help organize the process. The guiding tools are accompanied by a short Introductory Note on the Paradigm Shift from diploma-recognition based to competency-based master's admission. ${ }^{1}$ This article ${ }^{2}$ is a more elaborate version of that introductory note, reflecting also the progress in thinking and tool development since the start of the project. It is intended both for users of the Guiding Tools who seek more background and detail, and for readers with a general interest in the topic. For users of the Guiding Tools, it may give them additional reasons and arguments that they may find useful to increase commitment in their own university.
\end{abstract}

Keywords: Higher education; Europe; master's admission; diverse classroom; competency-assessment; internationalisation.

*Kees Kouwenaar (kees.kouwenaar@vu.nl) is senior advisor international strategy at the Vrije Universiteit, Amsterdam. He is also project manager of the Mastermind Europe project, funded as a Strategic Partnership in key action2 of the Erasmus+ programme.

1 A competency-assessment approach to master's admission should not be confused with Competency-Based Education.

2 The author acknowledges the support received from all members of the Mastermind Europe project team; outside the team, special acknowledgement is due to Robert Wagenaar (Tuning) and to Bas Wegewijs (Nuffic/Naric). 


\section{Introduction}

Higher education and research have become increasingly international in character. Educational programmes are no longer designed with only domestic students and employers in mind. Increasingly, the focus is also on international students and a globalised labour market.

Global rankings, whatever methodological critique they may invoke, are here to stay and have a significant impact on Higher Education (HE) strategies and reform efforts.

In the European context, the Bologna reforms are a regional manifestation of general globalisation trends and their impact on internationalisation of higher education. But globalisation has a fundamental impact on graduate education in other regions as well: In the United States, where the mere numbers of international students in graduate programmes is becoming a driver of change; and in many parts of the world, where government policies aim to create or strengthen Flagship universities and to concentrate the brunt of the nation's graduate and research effort there.

Graduate programmes in Europe and in other parts of the world are becoming more explicit in the meta-cognitive learning outcomes. Besides proficiency in their area of academic or professional expertise, graduates from European master's programmes are expected to have other competencies like analytical and communication skills, capacity for interdisciplinary and creative thinking, group work competencies - all in an increasingly intercultural setting. This development, loudly and widely called for by labour market actors, is reflected for instance in the evolution of the Qualifications Frameworks, in the results of the Tuning process, in the Dublin ${ }^{3}$ Descriptors in Europe and parallel developments towards Degree Profiles elsewhere.

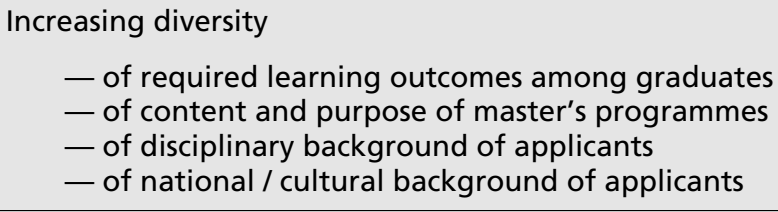

We witness a broadening of our perception of HE degrees and programmes beyond a focus on academic - often mono-disciplinary - content and

3 The term Dublin Descriptors to the cycle descriptors (or "level descriptors") which were developed between 2001 and 2004. The Dublin Descriptors have since been incorporated in the Qualification Framework of the European Higher Education Area in 2005. 
subject specific knowledge and skills. We now increasingly see descriptions of HE programmes and degrees also in terms of learning outcomes and sets of competencies; knowledge and technical skill did not lose importance, but are supplemented with non-cognitive skills and attitudes, which are seen as important for success in work and life. Identification of critical professional tasks and roles, and challenging professional situations, is used as a tool to bring together these cognitive and meta-cognitive aspects in a way that is recognizable for the professionals in the field.

A separate but related trend is that towards multidisciplinary, interdisciplinary and transdisciplinary master's programmes. These, by necessity, look for applicants from a variety of disciplinary backgrounds, making a one-size-fits-all knowledge prerequisite dysfunctional.

Thus, graduate programmes across the globe and across Europe face the need to attract students from a more diverse background, ${ }^{4}$ as well as the need to have a closer look at the meta-cognitive dimension. They will get applicants from other universities in their own country, from other countries in the region, from other world regions. An increasing number of master's programmes is actually seeking applicants from a diverse variety of disciplinary background. Thus, they are faced with applications from a wider variety of subject knowledge and skills as well as a wide variety of educational systems. And they need to assess if these applicants will be able to reach all relevant learning outcomes of the graduate programme: not only the (cognitive) learning outcomes connected to subject-specific knowledge and skills, but also the (meta-cognitive) learning outcomes that relate to the student's general academic ability and personal competencies and traits.

Over the next few years, an increasing number of academic master's directors will see the need for their admission process to evolve from "recognition of diplomas" to "assessment of competencies". This requires a breach from tradition, a paradigm shift.

Traditionally in continental Europe, we tend to see admission to a master's programme as a right which all students have who successfully completed the preceding bachelor's programme at the same university. To have the adequate preceding bachelor's is both necessary and sufficient for admission - to borrow a concept from mathematics. This right of admission

${ }^{4}$ Council of the European Union, "Council Conclusions on the Global Dimension of European Higher Education" (EDUCATION, YOUTH, CULTURE and SPORT meeting, Brussels, 25-26 November 2013), accessed July 23 ${ }^{\text {rd }}$, 2015, http://www.consilium.europa.eu/ uedocs/cms_data/docs/pressdata/en/educ/139717.pdf. 
can also be granted to other students with a bachelor's degree from outside: if it is sufficiently equivalent.

There has been a significant evolution of the way in which we decide if an "outsiders" bachelor's is admissible. Part of this article is dedicated to a description and analysis of this historical process - in which the Lisbon Recognition Convention plays a key role. ${ }^{5}$

On a different note, we see an increasing call to define admission requirements thinking "backwards": in this approach, the (externally oriented) objectives of the master's programme define the (internally oriented) designated learning outcomes. The learning outcomes in their turn define the curriculum; and the curriculum finally defines the admission requirements. This changes the admission concept from the question "who has the right to be admitted" to "how do we find the students who best fit in the master's programme?" This is the topic of the Mastermind Europe project initiated in 2014, which is discussed in this paper.

In this sense, the trend from diploma-recognition to competencyassessment as the basis for admission to master's programs fits well in the overall focus on (intended and achieved) learning outcomes. Neither "learning incomes" nor "incoming learning outcomes" is an expression that makes any sense in English; we will continue to use the term "entrance requirements" for want of a better term - more congruent with the Learning Outcomes terminology.

In the next paragraphs, we will delve a little deeper in these general shifts in the nature and purpose of master's programmes in Europe. Then we will zoom in on the paradigm shift for admission to master's programmes.

\section{Paradigm shift: Higher education degrees and programmes}

University degrees in Continental Europe are a product of history. Before the Bologna reform process, most systems of Higher Education in continental Europe knew only one degree before the doctorate. The basic idea of the pre-doctorate degree (Magister, Doctorandus, Maîtrise, Laurea, etc.) was that of the second-last step in the trajectory to become a full member of the Academic community. The final step of course was - and is - the doctorate / PhD.

Students of research universities were a small segment of their age group, groomed to become researchers like their professors. Their pre-

${ }^{5}$ See also the separate report of Prof Pavel Zgaga from Ljubljana University (forthcoming). 
doctorate degree was the proof that they were ready for the final step: conducting independent (but supervised) scholarly research, leading to the degree of Doctor as the proof of competence in research and university teaching.

This notion - that university education was intended to reproduce scholars, has already for long been an illusion to some extent. In Engineering, Business, Medicine, and Law - not the least populated parts of the university - this has been very obvious. Especially since the expansion of university education since the second half of the 20th century, more and more university graduates never pursued - or aimed to pursue - a career within academia.

Indeed, more and more university graduates even found themselves in gainful employment in professions which had little to do with the academic discipline in which they graduated. Employers and other stakeholders of the labour market stress the importance of "soft skills" of university graduates which enable them to work successfully in teams; diverse teams in academic, and increasingly also cultural terms.

In the knowledge-and-network-society, it is the combination of whatyou-know and whom-you-know, the ability to use one's expertise effectively in networks, that decides what value one can bring. But nonetheless, the notion was there and still persists - in varying degrees among across the disciplines - that only students with potential for a scholarly career are 'real' students or 'really interesting' students.

Higher education programmes have evolved over history; they have been shaped to a large degree by the professors in the discipline. These professors naturally have a strong focus on research and on the cognitive dimension: on the knowledge and technical skills, and on the methodological and theoretical framework belonging to that particular discipline. In fact, even where they recognize the importance of the soft skills, they often feel out of their depth in helping students to achieve those skills and in assessing if they have indeed achieved them.

Traditional academic studies have the outward appearance of a collection of subject oriented courses taught by subject specialists, completed with a thesis to prove scholarly competences. How these together constitute a coherent programme leading to a well-educated specialist was a seldomasked question. The programme's coherence was accepted as a time-created fact-of-life rather than analysed, designed and constructed.

When HE systems moved over to the three-tier system - of bachelor's, master's and PhD degree - of the Bologna process, the old notions persisted. But over the last decades, also new ideas about higher education and HE degree programmes have surfaced: the value of study abroad, the notion of 
an open European Higher Education Area, ECTS, the Tuning process, the evolution of a European as well as National Qualification Frameworks, the notion of Degree Profiles with learning outcomes and competencies (including, but not limited to, subject specific knowledge and skills) and quality standards, all have attracted broad attention among educationalists and more limited attention among subject specialists.

All of these developments are directly related to outcomes of education and comparison of these outcomes. A slightly different, but related topic is that of quality assurance. This has also been a prominent element in recent developments, e.g. with the development of Standards and Guidelines for quality assurance in the European Higher Education area ${ }^{6}$. Quality assurance and its contribution to accountability in HE is not at the centre of this argument or of the Mastermind Europe project. To the extent that the project contributes to more measurable outcomes of higher education process, it may help to strengthen the outcome-part of quality assurance mechanisms, which tend to have a more heavy focus on process elements.

Below, we will describe some of these phenomena in somewhat more detail.

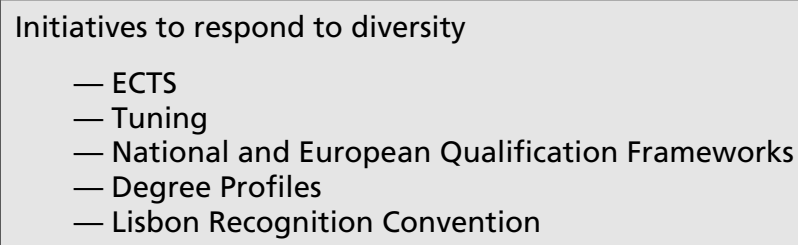

\section{II.1. ECTS}

The European Credit Transfer System ${ }^{7}$ was developed already within 2 years after the start of the first ERASMUS programme, with dr. Fritz Dalichow as the driving force. ${ }^{8}$ At the outset, it was intended primarily as a means to transfer credit for students who spent a period abroad in the context of their home university degree program. But over the years, it has evolved

${ }^{6}$ ENQA e.a., "Standards and Guidenlines for Quality Assurance in the European Higher Education Area", accessed December 6 ${ }^{\text {th }}, 2015$, https://www .eqar.eu/fileadmin/documents/e4/ ESG_-_draft_endoresed_by_BFUG.pdf.

${ }_{7}$ See ECTS Users Guide for an extensive description.

${ }^{8}$ See Dalichow, Fritz. "European Community Course Credit Transfer System." Higher Education in Europe 15.2 (1990): 72-73. 
into a broad range of experiences, concepts and tools that are also useful in the design, description and delivery of teaching programs, helping to integrate different types of learning. ${ }^{9}$ It creates a common language for education, independent of delivery mode (in the classroom, at the workplace, through distance, full-time or part-time), and in formal, informal or nonformal learning contexts. The ECTS philosophy and its tools have been an important source of inspiration of the Bologna process and at a later moment have been aligned with other elements of it, including the European Qualifications Frameworks. It offers an extensive and authoritative glossary, also including descriptions of 'learning outcome' and 'competence' discussed below in comparison with the Tuning descriptions of the same concept - , as well as samples of learning outcomes.

\section{II.2. Tuning}

TUNING Educational Structures in Europe started in 2000 as a project to link the political objectives of the Bologna Process and at a later stage the Lisbon Strategy to the higher educational sector. Over time Tuning has developed into a Process, an approach to (re-)designing, develop, implement, evaluate and enhance quality (of) first, second and third cycle degree programmes. The Tuning outcomes as well as its tools are presented in a range of Tuning publications, which institutions and their academics are invited to test and use in their own setting. The Tuning approach has been developed by and is meant for higher education institutions.

The name Tuning is chosen for the Process to reflect the idea that universities do not and should not look for uniformity in their degree programmes or any sort of unified, prescriptive or definitive European curricula but simply look for points of reference, convergence and common understanding.

The protection of the rich diversity of European education has been paramount in Tuning and in no way seeks to restrict the independence of academic and subject specialists, or undermine local and national authority.

Tuning focuses not on educational systems, but on educational structures with emphasis on the subject area level, that is the content of studies. Whereas educational systems are primarily the responsibility of governments, educational structures and content are that of higher education institutions and their academic staff.

From: Tuning website (http://www.unideusto.org/tuning)

\footnotetext{
${ }_{9}^{9}$ ECTS Users Guide, p.6
} 
The Tuning Methodology was developed to enhance understanding and comparability of curricula, with a key role for the academic experts in the subject concerned. These academics looked at generic and subject specific competences, at ECTS as a system for accumulation of achieved learning outcomes, at approaches to teaching and learning and approaches to assessment, and finally also at the role of quality assessment.

For new programmes, Tuning developed a model for the design and implementation of curricula,$^{10}$ which proceeded backwards: Based on an external needs analysis and ensuing degree profile, it worked through degree objectives and designated learning outcomes to required subject-specific and generic academic competences. From these it went towards the curriculum's content and structure, with defined learning outcomes and teaching, learning $\&$ assessment modes for each component of the curriculum.

The Tuning experts were well aware that the Bologna reform requires that each of the three cycles have their specific sets of learning outcomes and competences: for access to the next cycle as well as for entry into the labour market. With learning outcomes also as the articulation of what is needed for admission to the next cycle, the connection between learning outcomes and admission requirements becomes obvious.

Tuning made a distinction between:

a) learning outcomes as a measurable result of a learning experience which allows us to ascertain to which extent / level / standard a competence has been formed or enhanced. Learning outcomes are not properties unique to each student, but statements which allow higher education institutions to measure whether students have developed their competences to the required level state the students know, can demonstrate, and understand after a specific unit of the curriculum (course unit); and

b) competences which is seen as a quality, ability, capacity or skill that is developed by and that belongs to the student.

This set of definitions differs from the definition in the ECTS Users Guide ${ }^{11}$ also quoted by Kennedy: ${ }^{12}$

${ }^{10}$ Jenneke Lokhoff et al., eds., A Tuning Guide to Formulating Degree Programme Profiles. (Bilbao, Groningen, and The Hague: Universidad de Deusto, 2010).

${ }^{11}$ European Commission ECTS Users' Guide, 2015, p 72 \& 67; downloaded from http:// ec.europa.eu/education/library/publications/2015/ects-users-guide_en.pdf on 2-11-2015.

12 Declan Kennedy, Writing and using learning outcomes: a practical guide (University College Cork, 2006). 
Learning outcomes are statements of what a student is expected to know, understand and/or be able to demonstrate after completion of a process of learning.

Competence is the ability to use knowledge, skills and personal, social and/or methodological abilities, in work or study situations and in professional and personal development.

The key difference between a) learning outcomes and b) competencies doesn't lie in the fine line between "... what a student is expected to ....." and "... the ability to use ...". It is rather in the zooming in of the "learning outcomes" definition on the specific condition of "... after the completion of a process of learning." Learning outcomes may in practice be more specific, "smaller" than competencies. But the key distinction is that learning outcomes are the result of a learning process; in other words, learning outcomes are a specific kind of competencies, namely those that were achieved through a learning process.

As the ECTS definitions are both more concrete and aligned with the European Qualifications Framework, we will use the ECTS definitions in the article and in the Mastermind Europe project. But there is no real contradiction between the Tuning and the ECTS definitions, and it is still valuable to look at the distinction in Tuning within the broad concepts of learning outcomes and competencies.

Tuning distinguishes three types of generic competences:

- Instrumental competences: cognitive abilities, methodological abilities, technological abilities and linguistic abilities;

- Interpersonal competences: individual abilities like social skills (social interaction and co-operation);

- Systemic competences: abilities and skills concerning whole systems (combination of understanding, sensibility and knowledge; prior acquisition of instrumental and interpersonal competences required).

In the context of the Mastermind Europe project (which will be explained later in this document), we may note that this distinction among competencies can also be used to distinguish between categories or aspects of learning outcomes. The first two types are similar to the "academic competences" and "personal competencies and traits" in the Mastermind Europe project.

The Tuning methodology claims that the use of learning outcomes allows for much more flexibility than more traditional - knowledge-focused - study programmes, because they show that different pathways can lead to comparable outcomes. 
The Tuning methodology further argues that a focus on learning outcomes and competences helps to get away from the curriculum as a mere collection of the fields of interest of the teaching staff and/or as a collection of study points. It helps to move towards a student centred process of achieving the skills and knowledge required by the discipline and by society. In the Tuning methodology, each module or course unit in the curriculum should have its designated role in furthering the achievement of subject-related knowledge and skills as well as contributing to the development of a limited number of the generic competences identified for the degree profile.

In the words of Robert Wagenaar, ${ }^{13}$ Tuning's unique contribution is the alignment of the concepts of "competences" and "learning outcomes", relating both concepts to the (degree) profile of the educational programme.

The focus of Tuning on competences and learning outcomes was not new or unique. Wagenaar refers to a 1995 article of Robert Barr and John Tagg; ${ }^{14}$ the Lisbon Convention of $1997^{15}$ showed a similar tendency towards a functional approach of degrees: it calls for a comparison of what degreeholders know, understand and are able to do, rather than comparison of length of study or type of courses.

But Tuning was very successful in setting the agenda, not least because it managed to get embedded both in the Bologna reform process and the Lisbon Strategy of the European Union.

On a different footing, the OECD's DeSeCo project, launched in $1997,{ }^{16}$ identified:

a) Competencies to use tools effectively (i.e. language, knowledge, technology);

b) Competencies to interact in heterogeneous groups (building personal relationships; working in groups, managing conflicts); and

c) Competencies to act autonomously (see oneself and act in the bigger context, plan for the future, defend $\&$ assert rights and needs).

${ }^{13}$ Robert Wagenaar, "Competences and Learning Outcomes: A Panacea for Understanding the (new) Role of Higher Education?," Tuning Journal of Higher Education 1, no. 2 (2014): 279-302.

${ }^{14}$ Robert B. Barr and John Tagg, "From Teaching to Learning. A New Paradigm for Undergraduate Education," Change. The Magazine for Higher Education 27, no. 6 (1995): 1325, available at: http://www.athens.edu/visitors/QEP/Barr_and_Tagg_article.pdf.

15 "The Lisbon Recognition Convention [Main Documents]," Council of Europe, accessed February $19^{\text {th }}, 2015$, http://www.coe.int/t/dg4/highereducation/recognition/lrc_EN.asp

${ }^{16}$ Dominique Simone Rychen and Laura Hersh Salganik, eds., Key Competencies for a Successful Life and a Well-Functioning Society (Göttingen: Hogrefe and Huber Publishers, 2003), 5 . 
This approach, although interesting, seems less widely used within the context of HE degree programmes.

\section{II.3. National and European Qualifications Frameworks}

In 2005, the EU Education ministers decided to work towards an overarching framework of qualifications in the European Higher Education Area $^{17}$ and committed themselves to elaborating national Qualifications frameworks before 2010. The EHEA qualifications framework is connected to the European Qualifications Framework initiated by the European Commission, which uses 8 levels to cover the educational edifice from the basic levels of secondary education and vocational education and training (VET) to the $\mathrm{PhD}$, with level 5 to 8 overlapping with the HE notions of the short cycle, $1^{\text {st }}, 2^{\text {nd }}$, and $3^{\text {rd }}$ cycle Higher Education in the EHEA qualifications framework $(\mathrm{EQF})$.

The EHEA framework describes the outcomes of Higher Education at the first cycle, second cycle and third cycle levels, using the language of competencies to do so. It refers to the ability to "demonstrate knowledge and understanding" in the specified field, the ability to "apply" such knowledge and information in - professional or academic - environments of increasing complexity and uncertainty, to "formulate judgements" taking social and ethical dimensions into account, to "communicate" about their field with specialist and non-specialist groups, and to "continue learning" in an autonomous and self-directed manner. As stated in the 2009 report of the Coordination Group for Qualifications Framework: 18 "Developing and describing learning outcomes is, in the view of the Coordination Group, one of the greatest challenges with which the European Higher Education Area will continue to be confronted over the next few years and will require continued exchange of experience across the EHEA."

${ }^{17}$ European Higher Education Area [EHEA], “The Framework of Qualifications for the European Higher Education Area," accessed December 12, 2014, http://www.ehea.info/ Uploads/QF/050520_Framework_qualifications.pdf ; Bologna Working Group on Qualifications Frameworks, "A Framework of Qualifications of the European Higher Education Area" (Copenhagen K: Ministry of Science, Technology and Innovation, Denmark, 2005), accessed December 12, 2014, http://www .ond.vlaanderen.be/hogeronderwijs/bologna/ documents/050218_QF_EHEA.pdf

${ }^{18}$ BOLOGNA PROCESS Coordination Group for Qualifications Framework, "Report on Qualifications Frameworks" (Strasbourg: Council of Europe, 2009), accessed December 12, 2014.http://www.ond.vlaanderen.be/hogeronderwijs/bologna/conference/documents/2009_ QF_cg_report.pdf 
The paradigm shift from descriptions of HE programmes in terms of years of study to learning outcomes - as statements of what a learner is expected to know, understand and/or be able to do - is described by Karseth and Solbreke. ${ }^{19}$ They warn that the shift towards an approach to HE programmes that is more oriented on learning outcomes and competencies is complex and time-consuming.

The EHEA qualifications framework does not make an analytical distinction between various kinds of competences, such as subject-related, general academic and personal/interpersonal competencies.

As noted in the EHEA working Group report ${ }^{20}$ qualifications frameworks facilitate recognition by providing complete and reliable information on quality, workload and level; by emphasizing and describing learning outcomes, in particular generic learning outcomes; and by providing some information on profiles and specific learning outcomes, even if these will need to be complemented by further information if the profile of a given qualification is important to the purpose for which recognition is sought.

On the EHEA Bologna Process website, ${ }^{21}$ an overview is provided of the current state of affairs of national Qualifications frameworks development. By December 2014, nine European countries had sent in a report on the compatibility of their National Qualifications Framework with the EHEA Qualifications framework. Some reports also contain detailed information on the national Qualifications framework and the descriptors for the various cycles; others concentrate on the compatibility issues. According to Helg $\varnothing,{ }^{22}$ who analysed NQF development in Norway, Germany and the UK, there was broad support for the EHEA QF driven implementation of a NQF in Norway and Germany, while the NQF development in the UK actually preceded the European development (See also Young). In Germany, the strong "dual learning" system of apprenticeship-based and school-based learning was a positive factor. Helgøy shows that in each of these three countries, the focus of the NQF development was clearly on learning outcomes.

${ }^{19}$ Berit Karseth and Tone Dyrdal Solbrekke, "Qualifications Frameworks: The Avenue Towards the Convergence of European Higher Education?," European Journal of Education 45, no. 4 (2010): 563-76.

${ }^{20}$ EHEA Working Group, "Report by the EHEA working group on recognition," accessed December 6 ${ }^{\text {th }}, 2015$, http://www .ehea.info/Uploads/(1)/Recognition\%20WG\%20 Report.pdf

${ }^{21}$ European Higher Education Area [EHEA], "National Qualifications Frameworks," accessed December 12, 2014, http://www .ehea.info/article-details .aspx?ArticleId=69

${ }^{22}$ Ingrid Helgøya and Anne Hommea, "Path-Dependent Implementation of the European Qualifications Framework in Education. A Comparison of Norway, Germany and England [Version of Record], “ Journal of Comparative Policy Analysis: Research and Practice (2013): 1-16. 
The conceptual link between National Qualifications Frameworks and Learning Outcomes is not restricted to Europe. In his 2007 report for the ILO, Ron Tuck ${ }^{23}$ states:

A Qualifications Framework is an instrument for the development, classification and recognition of skills, knowledge and competencies along a continuum of agreed levels. It is a way of structuring existing and new qualifications, which are defined by learning outcomes, i.e. clear statements of what the learner must know or be able to do whether learned in a classroom, on-the-job, or less formally.

\section{II.4. Degree profiles}

Building on the work of the Tuning project and the earlier work of the ENIC/NARIC networks for recognition of academic qualifications, the European Commission supported two projects on "Competences in Recognition and Education" (CoRe 1 and 2) of Tuning and ENIC/NARIC together. The aim was to see if and how the notion of a "degree profile" could be used to improve recognition practice. CoRe 1 (2005-2007) focused on the question if "degree profiles", as developed in Tuning, can be a useful tool to enhance recognition of academic qualifications. It concluded that this is indeed the case, provided that enough similarity could be achieved in the terminology that universities use to describe the competences and learning outcomes.

CoRe 2 (2008-2010) consequently had one single objective. In the "Guide for formulating Degree Programme Profiles" (the final report of the CoRe2 project published on the Tuning website) it is stated as follows: "to provide a guide with instructions on how to describe the competences and learning outcomes of the degree profile in a consistent way, together with examples illustrating this." ${ }^{24}$

The Guide contains a "Template" with guidelines for constructing a degree profile. It offers a clear distinction between the concepts of "competences" and "learning outcomes" and provides information on how to formulate them. The CoRe 2 project has tested the template with both recognition and HE experts and a number of guinea pig universities.

${ }^{23}$ Ron Tuck, An Introductory Guide to National Qualifications Frameworks: Conceptual and Practical Issues for Policy Makers (France: International Labour Organization [ILO], 2007), 2.

${ }^{24}$ Lucie de Bruin, foreword to A Tuning Guide to Formulating Degree Programme Profiles, ed. Jenneke Lokhoff et al. (Bilbao, Groningen, and The Hague: Universidad de Deusto, 2010), 11-12. 
Indeed, the Guide articulates some of the key notions underlying the Mastermind Europe project, described in this "Paradigm shift" article:

Student-centred programmes require a change of paradigm and hence a change of mind set of the academic staff responsible for designing and delivering degree programmes. (....) degree programmes should be organised in view of their desired results. At present, in practice, many degree programmes are designed on the basis of tradition and the resources already available. Such programmes can be considered as 'input-based' and 'staffcentred'. In such programmes the emphasis is still placed on the individual interests of academic staff or on the existing organisation of studies. ${ }^{25}$

The Guide sees the Degree Profile as a concise expression of the key results of the programme. It focuses on 7 elements: a) Purpose, b) Characteristics, c) Employability \& further education, d) Education style, e) Programme competences, and f) Learning outcomes. ${ }^{26}$ For our purpose, we focus on the latter two: competences and learning outcomes.

In a similar vein, the University of Calgary gives specific information for each and every degree programme on: a) Key skills and knowledge, b) Sample job titles, and c) potential industries.

The Guide for formulating Degree Profiles makes a slightly different distinction between Competence and Learning outcome than the Tuning project did earlier. Where Tuning focuses on the distinction between course unit ( learning outcome) and complete degree programme ( competence), the Degree Profiles Guide argues that Learning outcomes are objectively measurable results of a learning experience, whereas Competences are qualities, abilities, capacities or skills belonging to an individual student. This seems a less sharp and clear distinction, as the defining elements are not mutually exclusive.

Like the Tuning publications, the Degree Profile Guide doesn't make a clear categorisation between competences related subject specific knowledge and skills, to general academic ability, and to personal competencies and traits. The Guide refers to the so-called "Dublin Descriptors" as the essential components of any degree programme.

Interestingly, the non-profit Lumina Foundation in the US published in 2011 a Degree Qualifications Profile. ${ }^{27}$ It is intended as a tool to help define

25 Jenneke Lokhoff et al., A Tuning Guide to Formulating Degree Programme Profiles (Bilbao, Groningen, and The Hague: Universidad de Deusto, 2010), 19.

26 Jenneke Lokhoff et al., A Tuning Guide, 20.

${ }^{27}$ Peter T. Ewell, "The Lumina Degree Qualifications Profile (DQP): Implications for Assessment" (Occasional Paper 16, Champaign: National Institute for Learning Outcomes Assessment, 2013). 
what students are expected to know and be able to do once they have obtained their degree. It was designed to challenge faculty and academic leaders to think about expectations for student learning outcomes across higher education. It still remains to be seen what impact the Lumina Degree Qualifications Profile will have on higher education in North America.

\section{II.5. Mastermind Europe project}

Thus, one sees that there has been a growing focus in higher education degree programmes on competences and learning outcomes - not instead of the focus on content and study load, but in addition to it. There is one important element in which the Mastermind Europe project differs in this respect from Tuning, Qualifications Frameworks and Degree Profiles.

The former initiatives all aim to articulate measurable Competences and Learning outcomes at the end of the education programme. They all aim to help and stimulate universities to send their graduates away with measurable and fairly homogeneous Competences and Learning Outcomes that are recognisable anywhere else.

The Mastermind Europe approach takes the perspective of the applicant student and the receiving institution: it aims to develop a toolkit for academic masters directors to identify:

a) which substance-related knowledge \& skills (SRKS);

b) which general academic competencies (GAC); and

c) which personal competencies and traits (PCT)

they require as minimal entrance requirements.

The chosen categorisation (SRKS, GAC, PCT) seems the best mix of theory found in psychological literature and practice within Higher Education with elements of competencies-based assessment.

The Mastermind Europe toolkit will also help to test whether individual applicants meet with these specific requirements and will help to provide prospective students with adequate information on these requirements, allowing for a successful match between students and master's programmes.

One may argue either way in terms of which approach - end-ofprogramme or start-of-programme - is more logical. If all HE institutions would define the Competences and Learning outcomes of their degree programmes in measurable terms (preferably not a myriad of them), that might be an excellent solution. But as (long as) this is not the case, a toolkit 
to assess the competences of applicants from a variety of backgrounds in discipline and educational system will prove to be of high value. It may indeed take a long time to achieve this excellent solution, as it requires consensus a) among subject specialists + educational specialists + government representatives, b) in all disciplines and interdisciplinary subjects, c) in all the countries of the European Higher Education Area.

Definition of measurable entrance criteria for specific master's programmes may prove to be easier. It requires only the consensus of subject specialists, educational and administrative stakeholders at the level of the programme and the institution - within the confines of the relevant regulations. It remains a challenge to identify common criteria and benchmarks at the entrance of master's programmes - but a common language is easier to create than agreement on what is going to be said in it. And the notion that master's programmes have differing entrance requirements may be less contentious than differing outcome levels of university degrees across Europe.

In a broader perspective, the difference sketched here between the 'endof-programme' approach in the various initiatives around learning outcomes, and the 'start-of-programme' approach in Mastermind Europe may in reality more a complementarity than a difference. Both approaches attempt to design a common language to articulate what students need to know, understand and/or be able to demonstrate: for successful conclusion or for successful admission to a program. Both approaches attempt to bridge the cleft between subject specialists in class and in the workplace - who need to recognize these learning outcomes or admission requirements as 'their own'and the educationalists and policy makers who want to have a terminology that allows for cross-country and cross-discipline comparisons.

\section{Paradigm shift: 'Outside' admission from exception to standard practice}

Admission to master's programmes of students who did their preceding bachelor's at another domestic or foreign research university grew from $17 \%$ in $2005 / 06$ to $27 \%$ in $2013 / 14$ in Dutch research universities. The total admission of students from 'outside' remained roughly stable at ca $40 \%$, because the period saw a significant drop in students transferring from Dutch Universities of Applied Science to research universities. At the Vrije Universiteit (VU University Amsterdam), the proportion on 'outside' master's students even exceeds $50 \%$. 
In France, the proportion of master's students 'not previously registered' at that university was $42,1 \%$ in 2012/13 (MESR).

Data from two countries in continental Europe are no solid evidence base, but they are indicative of a trend. The same can be said for the numbers of visits to the Mastersportal of StudyPortals, which have been increasing from less than 2 million in 2010 to more than half a million per month this year.

There is a clear trend in increase of master's applicants who were not before registered at that university. In other words: applicants from 'outside' are rapidly changing from an odd exception to at least a substantial minority of all students in the master's programme. This has consequences for the grounds on which decisions of admission and non-admission can be taken. When the overwhelming majority comes from the same university and in the same discipline as the master's programme, it makes sense to define admission in terms of that preceding bachelor's programme and treat 'outsiders' in that context. It makes sense to check if 'outsiders' are similar enough to the standard set by the bachelor's programme of the overwhelming majority.

But this standard loses validity when 25,30 or even 50 percent of the applicants have another educational background: from another domestic university, from another discipline or from another country. Then the argument becomes more pressing to have an admission practice, admission criteria and admission procedures that are more generic in nature, more applicable to a wider variety of cases.

The shift of 'outside' applicants from exception to at least significant majority has yet another consequence in terms of admission. With exceptional 'outside' admission, it is still possible to maintain the concept of 'right of admission' for the university's 'own students', but have a selective admission process for international students. For domestic students - usually including those from other universities in the country - the appropriate bachelor's diploma will suffice for admission; for international students, a qualitative assessment is often in place. But with the rising numbers of international applicants - and also in response to other trends sketched in par. 2 "Paradigm shift: HE degrees and programmes" - the question arises more and more whether admission should not become selective for domestic students as well.$^{28}$ If bachelor's graduates may choose between a wide variety of ensuing master's degrees, if master's programmes seek students from a wide variety of backgrounds, then a given bachelor's degree no longer constitutes a guarantee an automatic fit/match with master's programmes.

${ }^{28}$ Hans Pechar and Ada Pellert, "Austrian Universities under Pressure from Bologna," European Journal of Education 39, no. 3 (2004): 317-30. 
Under these conditions, pressure increases to have an admission framework that meets criteria of transparency and validity. Transparency in the sense that it can be understood also by potential students - and their sponsors - who are less familiar with the university and the HE system to which it belongs. Validity in the sense that the university and the master's programme monitor the actual predictive value of the elements that they use in the admission process and the admission decision.

\section{Master programmes}

Imagine a room with three doors as a metaphor of the bachelor's programme: one is the entrance, one (narrow) is the successful exit and one (broad) is for drop-outs. Those who pass through the door of success, immediately find themselves in the next room: that of the master's programme 'belonging' to the bachelor's. This symbolizes the pre-Bologna conceptual thinking in Continental Europe about the transition from bachelor's to master's.

Imagine now a similar room, also with three doors: one again is entrance, one (fairly broad) is the successful exit and one (fairly narrow) is for dropouts. But those who pass through the door of success, will find themselves in a large Hall, with an array of doors of different shapes and sizes. The Hall itself is a kind of maze; a person who wants to get to a certain door, needs to navigate before $\mathrm{s} /$ he can try to open it. This symbolizes competence-based master's admission.

The gradual shift from the room-to-room to the room-hall-room transition needs to be placed in a wider context. Part of this context is the evolution in thinking about the treatment of foreign qualifications from "equivalence" to "recognition" to "acceptance" (see the paragraph below). In this evolution, we may observe already elements of a "competency-assessment" approach in the practice of recognition, as demonstrated i.a. in the Lisbon Convention, in the Automatic Recognition policy and other developments in the NARIC network, such as the " 5 elements approach". Other parts of this context are the trend to define master's programmes 'backwards' from their intended outcomes, and the need for a more diverse classroom in many master's programmes and in European higher education as a whole.

The increased interest in Europe for standardised tests like the GRE (Graduate Record Examination) and GMAT (Graduate Management Admission Test) is also relevant in this context. This concerns European universities at which GRE and GMAT are used to assess applicants. But it 
equally concerns European students who submit to these tests in order to qualify for admission to graduate programmes in the US.

\section{Developments in Recognition}

Now, we will give a brief description of the developments in "recognition" and how these fit with the trend to focus more on learning outcomes, competencies, and comparability of degree profiles described in chapter 1 . From there we will turn to the notion of competency-based admission as an alternative to recognition of a degree.

\section{V.1. Evolution from equivalence to recognition to acceptance}

The analysis of more than 20 years ago of the evolution from equivalence to recognition to acceptance is still valid:

Equivalence, which requires an exact match in content as a precondition for recognition, has been gradually replaced by Recognition, which requires a match in functions and general level of the academic qualification. (...) However, the increased intensity of international cooperation and exchange between educational systems, which will remain highly diverse, calls for (...) a more tolerant and less mathematical approach $(\ldots) .{ }^{29}$

The 1994 article of this author describes how the General Directives (89/48/EEG; 92/51/EEC) of the European Union were leading the way towards such a more flexible "acceptance" approach, as these directives introduced the concept of "substantial difference": recognition could not be withheld on the grounds of any difference, but only on the grounds of substantial difference. The article also already underlined the factor of selective admission: where admission to a next phase is selective anyway, more flexibility in recognition of the degree is possible as it is only one of the selection criteria, which may be counterbalanced by other selection elements. Kouwenaar puts these developments in the perspective of the new Joint Convention, which was at the time being discussed and would become the Lisbon Recognition Convention in 1997.

Since the early General Recognition Directives of 1988 and 1992, the EU has moved further along this path. It has regulated that professionals must be

${ }^{29}$ Kees Kouwenaar, "Recognition Instruments in Europe," Higher Education in Europe 19, no. 2 (1994): 7-26. 
admitted into regulated professions, allowing the host country to require a compensatory measure in case of substantial differences between the training acquired and the training required in the host country. The professional has the choice between an adaptation period and an aptitude test. This system is now ruled by the "general system for the recognition of qualifications" (2005/36/EC), which will be amended by European Directive 2013/55/EU as of January 2016.

\section{V.2. Elements of competency-assessment in recognition practice}

The European Area of Recognition manual for Higher Education Institutions ${ }^{30}$ may be used to demonstrate that current recognition practice does indeed contain elements of competency-assessment, although often in an implicit manner.

The manual mentions the accreditation status of the university that issued the degree under review (See EAR HEI p 11). ${ }^{31}$ There is a formal as well as a qualitative aspect involved: without accreditation by a properly authorised and recognised body, the qualification is simply laid aside. But the kind of accreditation may - and does - also play a role. It makes a difference if the degree-issuing university is accredited as a "research university" or not. Recognition experts will - implicitly or explicitly — assume that a bachelor from a "research university" has a higher general academic competence than a bachelor from a HEI without such a research profile.

As recognition is also based - according to the manual and standard practice - on comparison of "degree profiles", it is thus also taking the "learning outcomes" and "competencies" into account.

Grades are generally considered to be of importance in the admission process. Assessment of grades implicitly assumes that high grades are a proxy for general academic competency. Still, good recognition experts weigh these grades in the context of educational culture and philosophy: high grades may mean excellent memorisation in one culture and may mean creativity and assertiveness in another.

Not mentioned, but often used in universities' admission practice, is the element of looking at research excellence (through Global Rankings or e.g.

${ }^{30}$ Nuffic (Netherlands organisation for international cooperation in higher education), The European Recognition Manual for Higher Education Institutions (The Hague: Nuffic, 2014).

31 Nuffic European Recognition Manual, 11. 
the Hirsch index of individual researchers). When research excellence is taken into account, it is used as an indication of educational quality in general and also as an indication of the general academic competencies of individual graduates.

\section{V.3. Current practice and developments in Recognition}

\section{V.3.1. Lisbon Convention and Criteria and Procedures}

As stated before, the 1997 Lisbon Recognition Convention is an important landmark in the development of recognition practice. It ordains that recognition should be the default practice and non-recognition should be the motivated exception; it lays the burden of proof (that recognition is not due) with the national or institutional authorities, where before the Lisbon Convention the burden of proof (that the foreign qualification as good enough) had lain with the applicant. And it rules that recognition may not be withheld on the basis of any difference - however minute - but only on the basis of substantial differences. Again, the burden of proof that such difference exists and is substantial, lies with the recognition authorities.

The ensuing documents on Criteria and Procedure have developed this concept further and have created a mechanism for the exchange of ideas and practices among recognition authorities; the intent was that this would lead to a convergence towards the best - most flexible - practice. However, as argued by Blomqvist ${ }^{32}$ and de Bruin,$^{33} 15$ years after the adoption of the Lisbon Recognition Convention there was and is still a "lack of systematic and fair application of LRC and subsequent texts.

\section{V.3.2. Automatic recognition}

This analysis of less-than-satisfactory results of recognition instruments and processes was shared at the level of the ministers of Education in the

${ }^{32}$ Carita Blomqvist, Lucie de Bruin, and Jenneke Lokhoff, "From Principle to Practice - Towards Fair Recognition in the EHEA," Journal of the European Higher Education Area, no. 04 (2012): 41.

${ }^{33}$ Lucie de Bruin, "With Both Feet on the Ground: EAR Projects, Instruments for Recognition," in The Lisbon Recognition Convention at 15: Making Fair Recognition a Reality (Council of Europe Higher Education Series No. 19), ed. Sjur Bergan and Carita Blomqvist (Strasbourg: Council of Europe Publishing, 2014), 207. 
European Higher Education Area. Automatic recognition is a fairly new concept that is explored by the 'pathfinder group on automatic recognition' in preparation of the Bologna Ministerial Conference in Yerevan 2015. As stated by the director of the Netherlands NARIC:

As the Education Ministers of the European Higher Education Area were not satisfied with the progress in solving recognition obstacles to mobility, they articulated the need to work towards automatic recognition of comparable degrees and called for a "European Area of Recognition" (EAR) and for the use of the EAR manual. ${ }^{34}$

The Pathfinder report ${ }^{35}$ had one main recommendation for the EHEA ministers: “... ensure that qualifications from other EHEA countries are recognised on an equal level with domestic qualifications, for example through enacting specific legislation to achieve this objective". In addition, it formulated a number of smaller steps, i.a. the review of national legislation, focus on time limits, promotion of the Diploma Supplement and others. ${ }^{36}$

While the Pathfinder Group on Automatic Recognition was still working on their recommendations, a new type of 'Policy experimentation' project was launched by the EC, with one of their priorities being the implementation of automatic recognition. In a remarkable new type of collaboration, a consortium of ministries of higher education, NARIC centres, higher education institutions, rectors' conferences and accreditation organisations applied for a project called Focus on Automatic Institutional Recognition (FAIR).

Quoting from the FAIR Project proposal ("Focus on Automatic Institutional Recognition"):

Automatic recognition follows the principles of the LRC and aims to simplify recognition processes by standardizing specific steps in the recognition process. Automatic recognition makes use of the national Qualifications frameworks in achieving recognition at system level ('a bachelor is a bachelor'). Automatic recognition therefore should reduce deviations in recognition decisions across the EU and EHEA, and lead to removal of mobility obstacles through more consistent evaluations and streamlining of recognition practices. Moreover it is expected it will also reduce the time needed for evaluations, which will serve students and

${ }^{34}$ De Bruin, "With Both Feet on the Ground," 207.

${ }^{35}$ EHEA Pathfinder Group on Automatic Recognition, "Report by the EHEA Pathfinder Group on Automatic Recognition" (EHEA 2014), available at: http://www.ehea.info/Uploads/ SubmitedFiles/12_2014/154205.pdf.

${ }^{36}$ EHEA Pathfinder Group, "Report," 7. 
employees wishing to study and work in another country. All in all, automatic recognition is widely expected to improve recognition practices substantially. ${ }^{37}$

In this manner, the project is hoped to address in particular the lack of awareness at the level of universities of all the progress made in recognition and stimulate the articulation of comparable learning outcomes and competencies at the end of university degree programmes. Thus, it will have to work within the confines of the sometimes less-than-specific and measurable descriptors in the Qualifications frameworks, degree descriptors and Tuning outcomes.

In addition, it attempts to enhance the technical expertise of administrative staff at universities who work on recognition of diplomas and credential evaluation. It aims to achieve more consistency across Europe in the use of what the NARICs see as the 5 core elements of a degree or diploma under evaluation: the level (in terms of the Bologna three stages of $\mathrm{B}-\mathrm{M}-\mathrm{PhD}$ ); the workload (for which the European standard unit of the ECTS applies), the quality (for which NARICs look at quality assurance mechanisms, while some also make use of e.g. the Carnegie classification and Global Rankings such as ARWU Shanghai Jiaotong ${ }^{38}$ ), the degree profile (e.g. theoretical versus applied, broad or specialized, mono- or multidisciplinary), and the learning outcomes (generic and subject-specific).

\section{Competency-based admission as an alternative to recognition}

The Mastermind Europe project is based on the hypothesis that neither the work on exit competencies (Tuning, Qualifications Frameworks, Degree Profiles) nor the work on Recognition (Lisbon Convention, Automatic Recognition) will offer sufficient tools to grapple with the huge and growing diversity in a) master's programmes and b) master's students in Europe. Lenient recognition on the basis of comparable degree profiles will not do the trick. Exit competencies - particularly when formulated through political negotiations - will seldom be specific and measurable enough to allow for automatic recognition. That is why an alternative approach needs to be explored: to formulate specific and measurable entrance requirements that

${ }^{37}$ Nuffic/NARIC, Key Action 3 EACEA/10/2014 Full proposal Application Form "Focus on Automatic Institutional Recognition, 26. Not public.

${ }^{38}$ NARICs also acknowledge that quality is a far too complex concept to be captured in such simple and contested instruments. 
allows for diversity of applicants and master's programmes and facilitate transparency and validity checks.

If we look for solid ground for a competency-assessment based admission to master's programmes in Europe, we can look at practice elsewhere and/or we can look in the literature. For relevant practice, it is useful to look at admission practice at North American research intensive universities. There are very fundamental and philosophical differences between university education in North America - in the USA and to a lesser extent in Canada - on the one hand and university education in the various parts in Europe. Indeed, the university traditions in the various parts of Europe also vary significantly between adherents to the Humboldtian tradition, Anglo-Saxon, French, Southern European, eastern European and North-western European university traditions.

But most continental European university systems have a common characteristic distinguishing them from Anglo-American universities, which is relevant to our paradigm shift. In Continental Europe, an educational diploma has not only value as the demonstration of successful completion of the educational programme; it also has value as an entitlement to a next step, be it admission to a subsequent educational programme or to a specific profession or position in society.

In North America and the United Kingdom, an educational diploma or degree gives no such right per se. Whoever has successfully completed an educational programme, may apply for admission to the next step. But this is not a right: additional requirements may be imposed or additional tests may be required to determine if the candidate is indeed suitable for this next step. This tradition of entrance selection has - regardless of any value judgement that might be passed - has given American master's programmes a wide and long experience in establishing admission criteria in the cognitive as well as in the meta-cognitive domain.

Looking at relevant experience elsewhere may be useful in order to learn from and emulate good practice, but also to learn from and fundamentally adapt practices that are not suited to the European context.

As part of the Mastermind Europe project, substantial efforts were and are undertaken to identify and analyse relevant literature from the relevant branches of psychology research..$^{39}$ This literature has been used to write the first public draft Guiding Tools ${ }^{40}$ as one of the tangible outcomes of the Mastermind Europe project. In the further course of the project, the

\footnotetext{
39 Social psychology, psychology of learning, behavioural psychology.

${ }^{40}$ See below and on http://mastermindeurope.eu/tools-and-reference-material/\#downloads
} 
collected literature will be made accessible (bibliographically, URL, short description).

If we look for solid ground in psychological and pedagogical literature, we first of all see a body of literature on personal traits and competencies on the one hand, and another body of literature on (testing of) academic competencies on the other.

On general academic competencies, the first phase of the Mastermind Europe project focused more on an analysis of existing standardized tests for general academic competencies than on psychometric literature. The reason for this was exactly the fact that these tests (notably GRE and GMAT) do indeed exist and have accumulated vast experience.

For the domain of personal dimensions, no well-developed tests with a focus on university studies were found and as a consequence, more attention was paid to more general literature on competencies - often in connection with the labour market. Here, we quickly arrive at the HEXACO model of 6 dimensions of human personality. ${ }^{41}$ HEXACO builds on the earlier "Big Five" model of human personality traits. Much more can be said about alternative models, about the distinction between personal competencies and personal traits, about competencies for study purposes or for the labour market, and on standard tests or intersubjective mechanisms to assess such personal competencies and traits. This is done in the Guiding Tool Personal Competencies and Traits which is part of the Mastermind Europe project explained below.

When we endeavour to build on both practice elsewhere and findings from research, we can see that there is - at least at first sight - some tension between both. Practice tends to favour a fairly simple demarcation between three categories: substance-related knowledge \& skills, general academic competencies, and personal competencies \& traits. Research and theory tends to see cognitive and meta-cognitive competencies as a continuum, in which a strict demarcation is at least to some extent problematic. Our project aims to provide practical tools to academic master's directors whose own background will more often be in their own subject area than in the pedagogics and didactics of university education. For that reason, we have decided to stay with the three categories indicated above. These may be a simplification of reality, but this disadvantage is effectively - we hope - countered by the integrative and holistic approach that we propose in the use of admission

${ }^{41}$ Michael C. Ashton et al., "A Six-Factor Structure of Personality-Descriptive Adjectives: Solutions from Psycholexical Studies in Seven Languages," Journal of Personality and Social Psychology 86, no. 2 (2004): 356-66. 
criteria from all three categories to answer the key questions in the admission process.

Thus, the Mastermind Europe project aims to develop Guiding Tools to help organize master's admission through competency-assessment with three related sets of competencies:

1. Substance-related knowledge and skills, which the student simply needs to possess to stand a fair chance to succeed in the master's programme and what it prepares for;

2. General academic competencies, with connotations of "academic level", maybe intelligence; sometimes called the "competencies of the mind"; and

3. Personal competencies \& traits, with connotations of social skills and motivation; sometimes called "competencies of the stomach" (personal) and "competencies of the heart" (interpersonal).

Such a categorisation - with adequate support in research in social psychology - offers the opportunity to develop a toolkit of instruments for competency-based admission. Key elements here are:

a) Define which criteria are importance for the master's programme

b) Set the minimum - or optimum - benchmark that applicants need to meet

c) Decide on mechanisms to decide if an applicant meets the benchmark in the designated criteria

d) Possibly design mechanisms that allow applicants to remedy deficiencies

e) Construct a process that is transparent to prospective students and allows to monitor validity and predictive value of the chosen criteria and benchmarks

f) Deal with legal, regulatory and cultural obstacles that may inhibit this approach.

In the remainder of the article, a description of the Mastermind Europe project as it set out since September 2014 is given, followed by an analysis of and reflection on the activities and results of the first year of this 3 -year project.

\section{The Mastermind Europe approach}

The categories of criteria and the key elements of a toolkit for competencybased master's admission are the cornerstones of the Mastermind Europe 
project, which under the ERASMUS+ programme (Key action 2: strategic partnerships) is set to develop and test just such a toolkit, strengthen the evidence base for the paradigm shifts described in this article and disseminate the results with the European Higher Education Area.

Mastermind Europe project

- Guiding Tools for competency-based admission

- Focus Groups with academic master's directors

- Pool of expert advisors

- Surveys to strengthen evidence base

The Mastermind Europe project is implemented from September 2014 to September 2017 by a Consortium of 11 members, directed by the Vrije Universiteit (VU University Amsterdam). Universities in the Consortium are the University of Helsinki, the University of Vilnius, the University of Graz, the University of Ljubljana and the Politecnico di Milano. In addition, the German Rectors' Conference and the Association of Catalan Public Universities are umbrella organisation members, as is the Academic Cooperation Association. The Consortium encompasses two private companies: StudyPortals and Ziggurat.

In the course of the three-year project, Mastermind Europe will produce draft and revised Guiding Tools to assist master's programmes to design and construct their own coherent competency-based admissions framework, with specific Guiding Tools on the various kinds of admissions criteria, language requirements and tools to organised admission efficiently. The first drafts have been published on the Mastermind Europe website (www. Mastermindeurope.eu) in the Summer of 2015, with further revisions expected in the course of the project.

The set of Guiding Tools will consist of:

a) A general introduction to the paradigm shift (a summary of this article).

b) A sketch of the place of master's admission within a) the chain of contacts between the student and the university from first recruitment to beyond graduation and b) the lifecycle of master's programme development.

c) A guiding Tool focusing on substance-related knowledge and skills.

d) A guiding Tool focusing on general academic competencies.

e) A guiding Tool focusing on personal competencies and traits.

f) A guiding Tool focusing on a coherent admission framework. 
g) A guiding Tool focusing on English language requirements.

h) A guiding Tool on admission software consistent with the competencybased master's admission.

Guiding tools on:

- Substance-Related Knowledge \& Skills

- General Academic Competencies

- Personal Competencies \& Traits

- Building a Coherent Admission Framework

- Language Requirements \& Tests

- Software that accommodates competency-based admission

The project is building up a small pool of experts in competency-based master's admission, available when universities feel the need for outside guidance and support in their effort to construct a coherent competencybased admission framework.

The draft Guiding Tools and the support by the experts is being tested in a series of regional Focus Group meetings, of which the first four (in Barcelona, Helsinki, Amsterdam, and Milano) were held in the course of 2015. A second round of Focus Group meetings will be held in the second half of the project.

To strengthen the evidence base of the project's underlying assumptions, surveys are carried out to collect quantitative and qualitative data on rules, criteria, tools and challenges that exist in master's programmes in Europe.

At the end of the project, an international conference will be organised to enhance dissemination, which is stimulated throughout the project by means of the Mastermind Europe website (www.Mastermindeurope.eu).

\section{One year Mastermind Europe: Analysis and reflection}

\section{VIII.1. Significant interest}

During the first year of the project, four draft Guiding Tools were published in addition to the Paradigm Shift report as an introduction to the Guiding Tools. Four Focus Group meetings were held to discuss the issue of Master's admission for a diverse international classroom: In Barcelona (April), Helsinki (May), Amsterdam (September), and Milano (December). The average number of participants was considerably higher than expected in 
the project plan, underlining the interest for the subject among academic master's coordinators in Europe.

This interest was also demonstrated by the large number of unplanned external events at which the notion of master's admission on the basis of assessment of competencies was shared with a wide variety of audiences: there were sessions at EAIE ${ }^{42}$ in September 2014 and September 2015, an internal workshop at the Vrije Universiteit Amsterdam (Februari 2015), and a workshop in the international Peer Learning Activity on Assessment of Learning Outcomes in the FABOTO ${ }^{43}$ in The Hague (October 2015); additional events are planned or foreseen for the first months of 2016 in Ljubljana, Moscow and Belfast. The interest for the new approach to master's admission was not limited to Europe: sessions were held for internationalization leaders and admission professionals in North America, as well as for protagonists of HE reform in Asia and specifically Japan.

In the course of 2015, a survey was conducted among the 1300 Englishtaught master's programmes in non-English speaking European countries; the survey focused on both facts and perceptions around master's admission. The publication of the analysis is forthcoming, while a second survey has been launched on the experiences of students in the application process.

A website was set up and used to disseminate information on the various events and publish the first 5 draft Guiding Tools. ${ }^{44}$

\section{VIII.2. Bridging practice and research; developing tools}

Looking back on the first year of the project, it seems clear that there is indeed merit in the efforts to bring together experience and expertise from various sources. In fact, this concerns a) the experience in universities already practicing elements of competency-assessment in admission, b) the concerns and needs of master's programmes confronted with increasing diversity, c) expertise in testing agencies such as ETS, and d) literature on scientific research on the topic. The draft Guiding Tools show the results of the first efforts on this score; more work will need to be done in the context of the Mastermind Europe project and beyond.

${ }^{42}$ EAIE: European Association for International Education.

${ }^{43}$ FABOTO: Facilitating the use of Bologna Tools.

${ }^{44}$ These are: A general introduction to the paradigm shift (a summary of this article); a guiding Tool focusing on substance-related knowledge and skills; a guiding Tool focusing on general academic competencies; a guiding Tool focusing on personal competencies and traits, and a guiding Tool focusing on a coherent admission framework. 
The development of the draft Guiding Tools in the first year of the project has been incremental: in the first half year of the project, rough drafts were produced and used at the first 2 Focus Group meetings, in Barcelona and Helsinki. These first rough draft versions were not yet 'tools' to speak of; they were collections and analyses of examples and literature and first attempts to structure these. On the basis of the first 2 Focus Group meetings - and considerable additional work by the experts - publishable draft Guiding Tools were developed which already contained some elements of tools: check lists, steps' sequences, question lists; the third Focus Group meeting in Amsterdam clearly showed the added value of these tools. But this development is not completed. There is still substantial work to be done to further develop the tools' character of the documents; this will need to be achieved in a re-iterative process between experts and users.

Part of the challenge in the creation of these tools is to reconcile the seemingly contradictory requirements of usability in very specific context (e.g. of study and country) and general usability and comparability across the wide variety of masters' programmes in Europe.

One particularly interesting finding has been that of the logical-abstract dimension of General Academic Competency, covered by the IE admissions test. $^{45}$

\section{VIII.3. Common framework with Tuning and European Qualifications Frameworks}

In the original Paradigm Shift report (see $\S 5$ above), Mastermind Europe's competency-assessment based approach to master's admission was placed somewhat in juxtaposition to the efforts to reach consensus on - and automatic recognition of - exit competencies. During the first year of the project, it has been increasingly clear that although this position may still be defensible in what regards to tools for admission to master's programs, there is no real tension between the approaches at the conceptual level: both the efforts aimed at Learning Outcomes, and at Automatic Recognition, and at a competency-assessment based approach to admission requirements for master's admission, work towards the same common framework of concepts and terminology for the purposes and processes in higher education.

${ }^{45}$ Formerly called "diagrammatical" by IE itself; now they refer to logical-abstract reasoning as the addition to the verbal and numerical comprehension and reason; see http:// www.ie.edu/iegat-masters-admission-test/ 
This can be clarified by looking at the example of the definition of Learning Outcomes. As quoted in $\S 2$ above, the ECTS User Guide gives the following definition of Learning Outcomes: Learning outcomes are statements of what a student is expected to know, understand and/or be able to demonstrate after completion of a process of learning.

In the Mastermind Europe project, it is now considered to offer a parallel definition of Admission Requirements: Admission requirements are statements of what a student is expected to know, understand and/or be able to demonstrate before the beginning of a process of learning.

More generally, it seems worthwhile to bring together terminology elements from projects and initiatives like Tuning, ECTS, EQF, QFHE, Automatic Recognition and the Mastermind Europe project and also the new CAHOLEE project. All these projects and initiatives have produced - and are producing - relevant concepts for knowledge, skills and attitudes and/or substance related knowledge \& skills, general academic competencies, and personal competencies and traits.

The fact that they have a different focus on the learning outcomes, design of curricula, and admission requirements for HE programmes only adds to the value of bringing them together in one common framework.

\section{VIII.4. Tasks and roles, critical thinking}

In developing the draft Guiding Tool for a Coherent Admission Framework, the power of the concept of tasks \& roles - briefly mentioned in $\S 1$ introduction - was until now only touched at the surface. The work of Jeroen van Merriënboer ${ }^{46}$ deserves a closer scrutiny in the remainder of the project, as does - yet unpublished - work by Daan Andriessen ${ }^{47}$ and Robert Coelen. ${ }^{48}$ In a similar vein, more work will need to be done to undercover layers and segments of critical thinking \& reasoning. This is indeed tested in the GRE and GMAT tests, but may need further refinement to make it more tangible for academics in specific programs. In a recent discussion at the Vrije Universiteit, the following concepts were articulated, which deserve further exploration and comparison with literature, i.a. in the context of GRE and GMAT: - (tendency towards) reproduction, -

46 Jeroen van Merriënboer and Paul Kirschner, Ten steps to complex learning: A systematic approach to four-component instructional design (Routledge, 2012).

${ }^{47}$ Looking at typical roles \& task in post HE professions such as 'advising', 'designing', 'producing', 'acting', and 'researching'.

${ }^{48}$ Looking for 'early career challenging tasks' for recently graduated professionals. 
(strength or weakness of) argumentation, - (shyness $\leftrightarrow$ openness to give or receive) criticism, - (strength or weakness of) analysis, - divergence (willingness to think out-of-the box and take unexpected viewpoints), (strength and weakness in written) presentation, - (ability to think in) analogies, - (ability to use) metaphors, - respect (for other opinions).

\section{VIII.5. Legal concerns}

The Mastermind Europe project from the start envisaged attention for the role of legal and regulatory obstacles to a competency-assessment approach to master's admission. In the course of the first year, indications were found that perceived regulatory obstructions may be more prevalent than actual obstructions. Furthermore, indications surfaced that there may be two distinct dimensions to the legal \& regulatory aspects: one - already foreseen in the project proposal - is that of regulations which explicitly forbid admission on the basis of any other criterion than a recognized degree. Another dimension - not foreseen from the outset - is that admission based on competency-assessment may be seen as contrary to more general principles of equity in admission and may lead to appeals by students who were not admitted.

\section{Conclusion}

The transition from bachelor's to master's in Europe is changing from a one-on-one transfer from a bachelor's programme to a master's programme into a many-to-many transition:

One-to-one: the vast majority of students continue after their bachelor's degree in the master's degree with which it forms a logical unity: in the same discipline at the same university.

Many-to-many: increasing numbers of students go to another university, maybe in another country, and in a (slightly) different discipline or an interdisciplinary master's programme.

This shifting attitude of students is only one of the trends which change the scenery for master's admission in Europe. There is a trend to focus on learning outcomes of master's programmes in broader terms than academic (scholarly) knowledge and skills; soft skills, meta-cognitive skills, communication skills, competencies. There is a trend towards more converging and generic outcome descriptors: what master's graduates know, can do and are able to understand. 
Key concepts in this perspective are the National and European Qualifications Frameworks, the Tuning Process, and the Dublin Descriptors.

Trends and developments in master's education run parallel with developments in thinking and practice in international recognition of academic degrees. The Lisbon Recognition Convention and its subsidiary texts have added tangible notions on procedures and criteria for (withholding of) recognition to the lofty declarations of good intentions. The idea has become accepted that recognition must/should be granted, unless the host country authorities can demonstrate substantial relevant deficiencies in a foreign degree. "Acceptance" of manageable differences is gaining ground over the prior concept of "Equivalence" in all details or at least in overall value and level. The ENIC/NARIC network - together with the Tuning experts - has set out a trajectory for "Automatic Recognition" to stimulate that such forward-looking recognition practice is wedded to the approach towards generic outcome descriptors and becomes daily practice at the level of universities as well as at the national level.

But even the most optimistic scenario for "automatic recognition" through "acceptance" will not provide an adequate solution to the problems of a) increased and increasing diversity in the offering of master's degrees and b) increased and increasing diversity in the background of applicants, both from within Europe and from other regions of the world.

More and more often, these existing tools are no longer sufficient to decide if an applicant from "outside" is admissible - whether in rightsbased admission ("all who are qualified") or in selective admission ("the best of the qualified"). If "outside" applicants are a relatively rare exception among a class of home-grown bachelor's, it may be acceptable to use assumptions like: "Students from high-ranked universities are always better for any master's programme than students from lower-ranked universities" or "The grade or GPA in the bachelor's demonstrates a student's intelligence". But when "outside applicants" become significant minorities or even the majority in class, more transparency and more validity - predictive value - is necessary to keep up both quality \& relevance to the post-graduation world and attractiveness to the prospective graduate students.

Increasing numbers of master's programmes in Europe want a diverse classroom, with students from various backgrounds in terms of universities, education systems and sometimes even disciplines. This development changes the key issue when admitting applicants for outside. The question changes from: "Does this student have a bachelor's which in sufficiently identical to our own preceding bachelor's" into "Does this student have what it takes to be successful in our programme?". 
Arguably it makes sense to cut this "what it takes" into three categories:

- Subject related knowledge and skills

- General academic competency and potential

- Personal and interpersonal competency and potential.

And the "what it takes" question consists of three parts:

- Which elements (competencies) are deemed essential for a specific master's programme?

- What measurable level is required at admission and how can this be tested/demonstrated?

- How can this assessment of competencies be organised in an admission process that is transparent for potential applicants and allows for monitoring its predictive value and validity over time?

As part of the Mastermind Europe project, a number of Guiding Tools are produced to assist academic master's directors who want to change from "diploma-recognition" based admission to "competency-assessment". The project is developing a toolkit which helps master's coordinators to decide if and to what extent they want to include academic and personal competencies in their admission process.

Guiding Tool 1: "Subject Knowledge and Skills, focuses on substancerelated knowledge and skills: if the notion of a full bachelor's in a specific discipline is dropped - for instance for multidisciplinary master's programmes - then what is the minimal knowledge and skill - related to the subject - that students need to command? And how does one organise a process to define these threshold markers with adequate support from academics and university leadership - and without a veto because of laws or regulations?

Guiding tools 2 and 3 focus on General Academic competencies and Personal Competencies \& Traits. Guiding Tool 4 focuses on a Coherent Admission Framework that brings together the key questions and specific categories. Guiding Tool 5 focuses on language requirements and tests. Guiding Tool 6 will discuss software programmes available on the market which allow to build in competency-assessment mechanisms into the graduate enrolment process.

The Guiding Tools are being tested in a number of Focus Group meetings with academic master's coordinators from various parts of Europe.

In the remainder of the Mastermind Europe project, the Guiding Tools and other instruments will - as sketched in $\S 7$ above - be further developed and improved to assist Master's coordinators who see the need for the 
transition to admission based on competency-assessment in a valid and transparent framework.

And most importantly, to help applicant students understand what is needed to get admitted, thus helping them to get admitted to suitable master's programmes.

\section{Bibliography}

Ashton, Michael C., Kibeom Lee, Marco Perugini, Piotr Szarota, Reinout E. de Vries, Lisa Di Blas, Kathleen Boies, and Boele De Raad. "A Six-Factor Structure of Personality-Descriptive Adjectives: Solutions from Psycholexical Studies in Seven Languages." Journal of Personality and Social Psychology 86, no. 2 (2004): 356-66.

Barr, Robert B., and Tagg, John. "From Teaching to Learning. A New Paradigm for Undergraduate Education." Change. The Magazine for Higher Education 27, no. 6 (1995): 13-25. Available at: http://www.athens.edu/visitors/QEP/Barr_and_ Tagg_article.pdf.

Blomqvist, Carita, Bruin, Lucie de, and Lokhoff, Jenneke. "From Principle to Practice - Towards Fair Recognition in the EHEA." Journal of the European Higher Education Area, no. 04 (2012): p.41-64.

BOLOGNA PROCESS Coordination Group for Qualifications Framework. "Report on Qualifications Frameworks." Strasbourg: Council of Europe, 2009. Accessed December 12, 2014. http://www.ond.vlaanderen.be/hogeronderwijs/bologna/ conference/documents/2009_QF_cg_report.pdf.

Bologna Working Group on Qualifications Frameworks. "A Framework of Qualifications of the European Higher Education Area." Copenhagen K: Ministry of Science, Technology and Innovation, Denmark, 2005. Accessed December 12, 2014. http://www.ond.vlaanderen.be/hogeronderwijs/bologna/ documents/050218_QF_EHEA.pdf.

Bruin, Lucie de. Foreword to A Tuning Guide to Formulating Degree Programme Profiles, edited by Jenneke Lokhoff, Bas Wegewijs, Katja Durkin, Robert Wagenaar, Julia González, Ann Katherine Isaacs, Luigi F. Donà dalle Rose and Mary Gobbi, 11-12. Bilbao, Groningen, and The Hague: Universidad de Deusto, 2010.

_- "With Both Feet on the Ground: EAR Projects, Instruments for Recognition." In The Lisbon Recognition Convention at 15: Making Fair Recognition a Reality (Council of Europe Higher Education Series No. 19), edited by Sjur Bergan and Carita Blomqvist. Strasbourg: Council of Europe Publishing, 2014: p.207-223.

Council of the European Union. "Council Conclusions on the Global Dimension of European Higher Education.” EDUCATION, YOUTH, CULTURE and SPORT meeting, Brussels, 25-26 November 2013. Accessed July $23^{\text {rd }}$, 2015. http://www. consilium.europa.eu/uedocs/cms_data/docs/pressdata/en/educ/139717.pdf 
Council of Europe. "The Lisbon Recognition Convention [Main Documents]." Council of Europe, accessed February 19 ${ }^{\text {th }}$, 2015, http://www .coe.int/t/dg4/ highereducation/recognition/lrc_EN.asp.

ECTS Users' Guide 2015: http://ec.europa.eu/education/library/publications/2015/ ects-users-guide_en.pdf.

EHEA Pathfinder Group on Automatic Recognition. "Report by the EHEA Pathfinder Group on Automatic Recognition.” EHEA, 2014. Available at: http://www .ehea. info/Uploads/SubmitedFiles/12_2014/154205.pdf.

European Higher Education Area [EHEA]. "National Qualifications Frameworks." Accessed December 12, 2014. http://www.ehea.info/article-details. aspx? ArticleId=69.

— "The Framework of Qualifications for the European Higher Education Area." Accessed December 12, 2014. http://www.ehea.info/Uploads/ QF/050520_Framework_qualifications.pdf.

Ewell, Peter T. "The Lumina Degree Qualifications Profile (DQP): Implications for Assessment." Occasional Paper 16. Champaign: National Institute for Learning Outcomes Assessment, 2013.

Helgøya, Ingrid, and Anne Hommea. "Path-Dependent Implementation of the European Qualifications Framework in Education. A Comparison of Norway, Germany and England [Version of Record] ". Journal of Comparative Policy Analysis: Research and Practice (2013): 1-16.

Karseth, Berit, and Tone Dyrdal Solbrekke. "Qualifications Frameworks: The Avenue Towards the Convergence of European Higher Education?". European Journal of Education 45, no. 4 (2010): 563-76.

Kouwenaar, Kees. "Recognition Instruments in Europe." Higher Education in Europe 19, no. 2 (1994): 7-26.

Lokhoff, Jenneke, Bas Wegewijs, Katja Durkin, Robert Wagenaar, Julia González, Ann Katherine Isaacs, Luigi F. Donà dalle Rose, and Mary Gobbi, eds. A Tuning Guide to Formulating Degree Programme Profiles. Bilbao, Groningen, and The Hague: Universidad de Deusto, 2010.

Nuffic (Netherlands organisation for international cooperation in higher education). The European Recognition Manual for Higher Education Institutions. The Hague: Nuffic, 2014.

Pechar, Hans, and Ada Pellert. "Austrian Universities under Pressure from Bologna." European Journal of Education 39, no. 3 (2004): 317-30.

Rychen, Dominique Simone, and Laura Hersh Salganik, eds. Key Competencies for a Successful Life and a Well-Functioning Society. Göttingen: Hogrefe and Huber Publishers, 2003.

Tuck, Ron. An Introductory Guide to National Qualifications Frameworks: Conceptual and Practical Issues for Policy Makers. France: International Labour Organization [ILO], 2007.

Wagenaar, Robert. "Competences and Learning Outcomes: A Panacea for Understanding the (new) Role of Higher Education?". Tuning Journal of Higher Education 1, no. 2 (2014): 279-302. 


\section{About the Author}

KEES KOUWENAAR (kees.kouwenaar@vu.nl) has over 30 years of experience in internationalisation and international cooperation in higher education. He is senior advisor international strategy at the Vrije Universiteit in Amsterdam (VUA), the Netherlands. At the Vrije Universiteit he served before as Strategic Programme manager Internationalisation and as director of the Centre for International Cooperation. Before moving to the VUA in 2008, he served as director of CILC (Centre for International Legal Cooperation), an NGO in legal and judicial development cooperation from 2002. He started his career in 1982 at Nuffic (the Netherlands organisation for International Cooperation in HE). At Nuffic, he worked as expert and director of NARIC-NEIC and served internationally as president of the NARIC network, chair of the EAIE professional sector for Admission and Credential Evaluation, and as key expert for the Lisbon Recognition Convention. His key areas of expertise are in international recognition of qualification, internationalisation of learning outcomes, comprehensive internationalisation strategy and practice, internationalisation of research, and capacity development in HE institutions. He has published on recognition, capacity development in $\mathrm{HE}$ and on strategies for internationalisation of HE. Kees Kouwenaar holds a 'doctorandus' degree in History from the Vrije Universiteit (comparable to BA + MA in History).

\section{Copyright}

Copyright for this article is retained by the Publisher. It is an Open Access material that is free for download, distribution, and or reuse in any medium only for non-commercial purposes; provided any applicable legislation is respected, the original work is properly cited, and any changes to the original are clearly indicated. 